\title{
A new cancer-testis long noncoding RNA, the OTP-AS1 RNA
}

2 Iuliia K. Karnaukhova ${ }^{1,2,3}$, Dmitrii E. Polev ${ }^{3, \# a}$, Larisa L. Krukovskaya ${ }^{1,3}$, Alexey E.

3 Masharsky ${ }^{3, \# a}$, Olga V. Nazarenko ${ }^{3}$, Andrei A. Makashov ${ }^{1,2}$, Andrei P. Kozlov 1,2,3*

4

$5 \quad{ }^{1}$ State Research Institute of Highly Pure Biopreparations, St. Petersburg, Russia

$6 \quad 2$ Peter the Great St. Petersburg Polytechnic University, St. Petersburg, Russia

$7 \quad{ }^{3}$ The Biomedical Center, St. Petersburg, Russia

$8 \quad$ \#a Current Address: RRC "Centre Biobank", St. Petersburg State University, St. Petersburg,

9 Russia

$11 *$ Corresponding author

12 E-mail: contact@biomed.spb.ru (AK) 


\section{Abstract}

Orthopedia homeobox $(O T P)$ gene encodes a homeodomain-containing transcription factor involved in brain development. OTP is mapped to human chromosome 5q14.1. Earlier we described transcription in the second intron of this gene in wide variety of tumors, but among normal tissues only in testis. In GeneBank these transcripts are presented by several 300-400 nucleotides long AI267901-like ESTs.

We assumed that AI267901-like ESTs belong to longer transcript(s). We used the Rapid Amplification of cDNA Ends (RACE) approach and other methods to find the full-length transcript. The found transcript was 2436 nucleotides long polyadenylated sequence in antisense to OTP gene. The corresponding gene consisted of two exons separated by an intron of $2961 \mathrm{bp}$ long. The first exon was found to be $91 \mathrm{bp}$ long and located in the third exon of OTP gene. The second exon was $2345 \mathrm{bp}$ long and located in the second intron of OTP gene. 
to protein-coding genes, and localization of this kind is beneficial in order to regulate the transcription of neighboring genes. Studies have shown that of lncRNAs play many roles in the regulation of gene expression. New evidence indicates that dysfunctions of lncRNAs are associated with human diseases and cancer.

In our study we found a new cancer-testis long noncoding RNA (OTP-AS1), which is an antisense of protein-coding cancer-testis gene (OTP). Thus, OTP-AS1 and OTP genes may be the CT-coding gene/CT-ncRNA pair involved in regulatory interactions. This is supported by the similar profile of their expression. OTP-AS1 may be of interest as a potential diagnostic marker of cancer or a potential target for cancer therapy.

Part of $O T P-A S 1$ gene (5'-end of the second exon) is evolutionary younger than the rest of gene sequence and is less conservative. This links OTP-AS1 gene with so-called TSEEN (tumor-specifically expressed, evolutionary novel) genes described by the authors in previous papers. experimentally $[2,3]$.

We mapped the sequence AI267901 to human genome using UCSC Genome Browser.

57 The studied sequence was found to be located on $5 \mathrm{q} 14.1$ in the second intron of the human 
We suggested that AI267901 and other similar ESTs are the parts of a longer RNA. In order to verify our hypothesis and to obtain complete nucleotide sequence of putative long RNA we used Rapid Amplification of cDNA Ends (RACE) approach.

\section{Results}

We assumed that AI267901 and similar ESTs belong to one long transcript so we used the Rapid Amplification of cDNA Ends (RACE) to find its and 3' ends. Results of the tworound amplification of the 5 ' end of the transcript are presented at Fig 1 . The figure shows the

PCR-product of 443 bp long. The obtained fragment was further cloned, propagated in E.coli and sequenced (S1 Sequence). The resulting sequence was aligned with the human genome. We mapped the $443 \mathrm{bp}$ fragment to the chromosome 5 and found that it consists of two exons (91 and 352 bp) separated by 2961 bp long intron (Figs 2 and 4).

Analysis of the exon/intron borders (Fig 2) demonstrated that the studied sequence is encoded by "plus" DNA strand of the chromosome $5, i$. e. located in antisense to the OTP gene. The first exon is located in the third exon of OTP gene, and the second one - in the second intron of OTP gene.

We were unable to extend the 3' end of the transcript using the RACE technique. Therefore to determine the 3 ' end of the transcript we performed the first strand cDNA synthesis with RT and oligo(dT) adapter primer followed by 2-round PCR. The results are presented at Fig 3. The obtained three fragments of different size were further cloned, propagated in E.coli and sequenced. We found that fragment №1 (see sequence in S2 Sequence) was 2311 bp long, polyadenylated, and located at the 5th human chromosome as an extension of the $443 \mathrm{bp}$ fragment found earlier with 318 bp overlapping of the AI267901 sequence (Fig 4). Fragment №2 was found to reside on the 3rd chromosome (chr3:14247460-14247871, data not shown). 
And, finally, fragment №3 (see sequence in S3 Sequence) was found to be polyadenylated, 940 bp long and also located on the 5th chromosome, fully matching the 3' end of the fragment №1 (Fig 4).

Using the BioEdit (v.7.2.5) software and UCSC Genome Browser we determined the sequence of the previously unknown gene located on chromosome 5 in antisense to the OTP gene. The corresponding transcript of the gene is $2436 \mathrm{bp}$ long and polyadenylated. This gene consists of two exons: the first exon is $91 \mathrm{bp}$ long and locates in the third exon of OTP gene, and the second one is $2345 \mathrm{bp}$ long and locates in the second intron of OTP gene. The exons are separated by an intron of 2961 bp long (Fig 4).

To obtain the full length sequence of this gene experimentally the 2-round RT PCR was performed. RNAs isolated from $293 \mathrm{~T}$ cells or uterus endothelium adenocarcinoma were used as templates. RT was performed with the oligo(dT) primer, PCR - with the full-forv and full-rev primers. The resulting fragment is 2436 bp long (Fig 5) as it was predicted by in silico analysis

(Fig 4). This full lenght transcript was cloned into TA cloning vector, propagated in E. coli and sequenced. Its sequence is presented in S4 Sequence.

The search of the possible open reading frames (ORFs) was performed using the ORF Finder webtool. We identified 10 ORFs coding for peptides from 20 to 62 amino acid long (S5 List).

Amino acid sequences of the identified ORFs were compared to the known proteins using Blastp algorithm. Homologous proteins were not found in humans or in other organisms.

Using RNAfold Web Server we modeled the secondary structure of the newly discovered gene mRNA (S6 Fig). This structure has a low free energy level $(-650.96 \mathrm{kcal} / \mathrm{mol})$ suggesting that this mRNA structure is thermodynamically stable. 
We demostrated that different parts of our gene have different evolutionary ages.

Orthologs of sequences located between 1-91st nucleotide and $600^{\text {th }}$ to $2436^{\text {th }}$ nucleotides were found in all Tetrapods, but othologs of sequence located between $92^{\text {nd }}$ and $600^{\text {th }}$ nucleotides were found only in Eutherian species, as seen on the phylogenetic trees (S7 and S8 Figs). The sequence conservation analysis was performed with Phylip tool integrated in USCS genome browser. We found that the sequence between 92nd and 600th nucleotides demonstrated low conservation in all genomes used for the analysis (Fig 6).

To assess the tumor specificity of expression of the newly identified gene we used commercial Clontech (USA) and BioChain (USA) cDNA panels corresponding to normal and tumor tissues. We also used cDNA panel made in our laboratory using clinical samples of tumors from various localizations and at different stages of progression (Biomedical Center human tumor cDNA panel, Russia). The gene expression was determined by PCR with primers specific to the most conservative part of the newly discovered gene - from 1012 to 1452 nucleotide (Fig 6, in yellow). In normal and fetal tissue cDNA panels, the minor specific signal corresponding to this fragment was detected in only one testis sample (Fig 7).

In BioChain tumor cDNA panels, the expression of newly discovered gene was detected in the following tumors: carcinomas of lung and bladder, adenocarcinoma of esophagus, small intestine, colon and ovary. The fragment was not found in brain astrocytoma, testis seminoma, carcinomas of breast, liver, kidney, fallopian tube and ureter, stomach and uterus adenocarcinoma (Fig 8a).

In the Biomedical Center human tumor cDNA panel the expression of the studied fragment was detected in five samples of mammary gland cancer $(19,246,250,251,252)$; in one sample of ovary cancer (6), hypophyseal adenoma (140) and bronchus cancer (17); in two samples of endometrial adenocarcinoma $(156,270)$, meningiomas $(45,63)$; and in all lymphoma samples $(31,67,82,92,102,94,113)$ (Fig 8b). Weak signals corresponding to the studied 
133 fragment were also found in samples of metastasis of squamous cell cervical carcinoma from uterus (2a-1), left (2a-3) and right ovaries (2a-4), and in one of two samples of squamous cell lung cancer (14). No signals were found in cervical carcinoma (2), cervical myosarcoma (13), seminoma (7), stomach cancer (108), leukemia (30), and in one of two samples of squamous cell lung cancer (12) (Fig 8b).

We also studied expression of the extended transcript of the newly identified gene on RNA isolated from different tumors (non-Hodgkin's lymphoma at stages II and IV, lymphadenopathy of unknown origin, invasive ductal breast cancer at stage II). cDNA was synthesized using oligo(dT) primer. We conducted 2-round PCR with the primers to the ends of the newly identified transcript (as-forv, as-rev). Results are presented at Fig 9. The fragment of $2378 \mathrm{bp}$ long was found in all studied samples, thus demonstrating the expression of the previously unknown gene in different tumors.

\section{Discussion}

In our previous papers $[2,3]$ we demonstrated highly tumor-specific expression of AI267901-like EST (earlier corresponding to cluster Hs.202247). This locus was expressed in 49 of 59 tumor samples of different localization and only in one sample of normal testis. We mapped the AI267901 sequence to the human genome using UCSC Genome Browser. The studied sequence was found to be located at $5 \mathrm{q} 14.1$ in the second intron of the human Orthopedia homeobox (OTP) gene (Figs 4 and 6).

Human OTP gene is the homologue of the murine Orthopedia gene and belongs to the homeodomain genes. Its function in humans is not fully characterized as yet. Expression of the OTP gene was found in the brain of 17 week old human embryo, supposing the potential role of this gene in brain development [4]. OTP is encoded by the "minus" strand of the 5th chromosome and consists of 3 exons and 2 introns. 
At the present time $O T P$ gene is actively studied as a prognostic marker for carcinoid lung tumors by several research groups. There are data showing the OTP gene expression only in lung tumors $[5,6]$ and bladder [6]. We have shown that OTP gene is expressed in a wide range of tumors of almost all localizations. This gene was expressed in 23 of 29 tumor samples of different localization and only in one sample of normal testis [3].

AI267901 is located in the intronic region of the OTP gene and must be absent in the mature Orthopedia homeobox mRNA. At the same time, our results show that AI267901 and OTP gene have similar expression profiles both in normal tissues and in tumors [3]. Therefore the AI267901 might be interpreted either as OTP transcript alternatively processed in tumors or as a separate transcript.

To find the complete nucleotide sequence of AI267901 we used the Rapid Amplification of cDNA Ends (RACE) and other approaches. As a result, we have obtained a $2436 \mathrm{bp}$ long sequence of the previously unknown gene located on the opposite strand of OTP gene. mRNA of this gene is polyadenylated and has two exons. The first short exon (91 bp) is mapped to the antisense strand of untranslated region (3'-UTR) of OTP gene. It is known that initiation sites of noncoding RNAs transcription are frequently located in the 3'-UTRs of protein-coding genes [7]. The second exon (2345 bp) is mapped to the antisense strand of $2^{\text {nd }}$ intron of OTP gene. The first and second exons are separated by 2961 bp intron (Figs 4 and 6). The sequence of the whole transcript is presented in S4 Sequence.

We have shown the expression of the full size newly discovered gene in human embryonic kidney 293 (HEK293) cell line and in uterus endothelium adenocarcinoma (Fig 5), and of the $2378 \mathrm{bp}$ fragment of the gene in the following human tumors: non-Hodgkin lymphoma stage II and stage IV, invasive ductal breast cancer stage II and lymphoadenpathy of unknown origin (Fig 9). Interestingly that several shorter sequences can be seen along with the expected fragment (2378 bp) at Fig 9. These fragments might be an alternatively spliced variants 
of the newly discovered gene in tumors. These fragments are being sequenced now in our laboratory.

The study of the expression of the conservative region of newly discovered gene in human tumors and normal tissues has shown that it was expressed in majority of the tumor samples studied, including tumors of brain, lung, esophagus, intestines, breast, bladder, uterus, ovary and in lymphomas (Fig 8), but among normal tissues only in testis (Fig 7).

The search of possible open reading frames (ORFs) was performed using the ORF Finder webtool. Amino acid sequences of the ORFs were short in comparison with the known proteins. Blastp algorithm did not show homologous proteins in humans or in other organisms.

The lack of significant ORFs suggests that we discovered a new tumor-specific long noncoding RNA (lncRNA). Thus, OTP- antisense RNA 1 gene is supposed to be a cancer-testis (CT) long non-coding RNA (lncRNA) gene. According to human non-protein coding RNA (ncRNA) gene nomenclature $[8,9]$ we assigned a symbol OTP-ASI (OTP - antisense RNA 1) to this gene. This gene symbol is approved by HUGO Gene Nomenclature Committee (HGNC).

We found that, despite the fact that most of the gene ( $\sim 1900$ nucleotides) appeared in Tetrapoda, the insertion of evolutionarily novel part occurred after Eutheria speciation (S8 Fig). This evolutionarily novel part locates between $92^{\text {nd }}$ and $600^{\text {th }}$ nucleotides on $O T P-A S 1$ sequence Most lncRNAs exhibit weak or untraceable primary sequence conservation [10, 11, 12]. Nevertheless conservative lncRNAs are described in the literature, e.g. MALAT1 gene [13]. OTP-ASI older part is also conservative as shown by Phylop analysis (Fig 6). The evolutionarily younger part ( $\sim 500$ nucleotides) of the OTP-ASI gene demonstrates much lower level of conservation according to analysis made by Phylop tool (Fig 6). Interestingly, all AI267901-like tumor-specific ESTs are mapped on this non-conserved Eutheria-specific region of the gene. This links OTP-ASI gene to so-called TSEEN (tumor-specifically expressed, evolutionary novel) genes described by the authors in previous papers [14,15, 16, reviewed in 17]. 
The $O T P-A S 1$ gene transcript is spliced and polyadenylated. mRNA of $O T P-A S 1$ gene shows low levels of free energy $(-650.96 \mathrm{kcal} / \mathrm{mol})$. This means that thermodynamic stability of the studied RNA is high. This possibly indicates to the existence of some functions of this gene.

Although functions of most lncRNAs are unknown, the number of characterized lncRNAs is growing and many publications suggest they play roles in regulation of gene expression in development, differentiation and human disease. IncRNAs may regulate proteincoding gene expression on both transcriptional and posttranscriptional levels [reviewed in 18]. Cancer-testis (CT) genes demonstrate similarity between processes of spermatogenesis and tumorigenesis. CT-antigens may serve as cancer diagnostic markers or as potential targets for anti-cancer vaccines. The large group of cancer-testis non-coding RNA (CT-ncRNA) was recently described by in silico methods [19]. Wang and co-authors described cancer-specific CTcoding gene/CT-ncRNA pairs (where the distance between the CT-coding gene and CT-ncRNA was $<100 \mathrm{~kb}$ ). The authors suggest that these pairs may be involved in self regulatory interactions. For example, it was demonstrated that meiosis-related extremely highly expressed crucial roles in carcinogenesis in lung adenocarcinoma [19].

According to our findings in this paper and elsewhere [3], OTP-AS1 gene as well as OTP gene may be CT-genes. Moreover, OTP-ASl gene is located at antisense to OTP gene strand. Thus, OTP-AS1 and OTP genes may be the CT-coding gene/CT-ncRNA pair involved in regulatory interactions. This is supported by the similar profile of their expression [3]. These genes may be targets for future cancer therapies.

Thus we have discovered a new cancer-testis long noncoding RNA which may have regulatory function. We assume that $O T P-A S 1$ gene may play a role in $O T P$ gene regulation. 
Part of this data was presented at the 2nd International Conference on the Long and the

\section{Materials and Methods}

a set of normalized single-strand cDNA, produced from poly $(\mathrm{A})+\mathrm{RNA}$ from various normal MTC ${ }^{\text {TM }}$ Panel I (Catalog no. 636742), Human MTC ${ }^{\text {TM }}$ Panel 2 (Catalog no. 637643), Human Immune System MTC ${ }^{\text {TM }}$ Panel (Catalog no. 636748) end Human Fetal MTC ${ }^{\text {TM }}$ Panel (Catalog no. 636747). According to the manufacturer's information, the panels were free from genomic DNA and were normalized to expression levels of four house-keeping genes. Each cDNA sample comes from a pool of tissue samples obtained from donors of different age and sex, with 2-550 donors in each pool, and the fetal tissue samples were obtained from spontaneously aborted fetuses at 18 to 36 weeks of gestational age. The quality of all samples we assessed by PCR using primers for the housekeeping gene GAPDH (data not shown).

\section{Tumor cDNA Panel}

A cDNA panel containing a total of 15 of cDNA samples were obtained from BioChain Instutute, USA (Catalog nos.: C8235544, C8235545, C82355546, C8235549). The samples were produced by the manufacturer from various human tumors obtained from surgeries. Each sample came from one patient and was histologically characterized. cDNA was produced from poly(A)+ 
mRNA that was free from genomic DNA and normalized by $\beta$-actin gene expression level. The quality of all samples we assessed by PCR using primers for the housekeeping gene GAPDH.

\section{Clinical Material}

In our work we also used samples of surgically excised tumors of various origins obtained in the Kirov Military Medical Academy (St. Petersburg, Russia). A total amount of 29 samples was obtained in our laboratory after a written informed consent of all participant patients. The use of the samples for gene expression studies was approved by the Ethical Committee of the Kirov Military Medical Academy and the Biomedical Centre (St. Petersburg, Russia). The tumors were histologically characterized. We studied the following tumor samples: stage II-III invasive duct mammary gland cancer (3 samples, patient codes: 250, 251, 252), stage III mammary gland adenocarcinoma (patient code 19), squamous cell cervical carcinoma, IV stage (patient code 2) and its metastases into uterus (patient code 2a-1), left (patient code 2a-3) and right ovary (patient code 2a-4), cervical myosarcoma, stage II-III (patient code 13), ovary cancer (patient code 6), moderately differentiated endometrial adenocarcinoma, stage II (patient code 156), moderately differentiated endometrial adenocarcinoma with metastases, stage III (patient code 270), seminoma (patient code 7), meningioma (patient codes 45, 63), hypophyseal adenoma (patient code 140), squamous cell lung cancer (patient codes 12, 14), bronchus cancer III stage (patient code 17), stomach cancer (patient code 108), chronic lymphacytic leukemia, stage IV (patient code 30), non-Hodgkin T-cell lymphoma, stage IV (patient code 31), lymphoadenpathy of unclear pathogenesis (patient code 67), non-Hodgkin lymphoma, stage II (patient code 82), Hodgkin's lymphoma, relapse, stage IV (patient code 92), hemolythic anaemia of unclear pathogenesis (patient code 94), non-Hodgkin lymphoma, stage II (patient code 102), non-Hodgkin lymphoma, stage IV (patient code 113), invasive ductal breast cancer at stage II (patient code 246). Additionally, we used human embryonic kidney 293 (HEK293) cell line. 


\section{RNA isolation and quality control}

Total RNA isolation from clinical material of human tumors was performed via routine procedure using guanidine isothiocyanate as described elsewhere [20]. RNA samples were treated with DNAse I, RNAse free (Sigma, USA) for $10 \mathrm{~min}$ at $25^{\circ} \mathrm{C}$ in order to remove any contaminating genomic DNA.

The concentration of isolated RNA was measured using Ultrospec ${ }^{\circledR} 3100$ pro following agarose gel electrophoresis by band intensity ratio of $28 \mathrm{~s}$ rRNA to $18 \mathrm{~s}$ rRNA [21].

The absence of the DNA in the RNA samples was determined by PCR using primers for as follows: $3 \mathrm{~min}$ of denaturation at $94{ }^{\circ} \mathrm{C} ; 40$ cycles of $30 \mathrm{~s}$ at $94{ }^{\circ} \mathrm{C}, 30 \mathrm{~s}$ at $68{ }^{\circ} \mathrm{C}, 30 \mathrm{~s}$ at 72 product of GAPDH. The gels were photographed under UV illumination.

\section{RACE (Rapid Amplification of cDNA Ends)}

We used MarathonTM cDNA Amplification Kit (Clontech) to obtain cDNA from uterus adenocarcinoma RNA samples according to manufacturer's protocol. Obtained two-strand cDNA was subjected to 5'- and 3'- RACE PCR.

5' - RACE PCR is two-round amplification using the gene specific forv1 (5'CGATGGATAAACAGGTCTCGTCTCTTCC- $\left.3^{\prime}, \quad \quad \mathrm{T}_{\mathrm{m}}=62^{\circ} \mathrm{C}\right), \quad$ forv1N 
GGCCAGGCGTCGACTAGTAC-3’) primers.

3' - RACE PCR is two-round amplification using the gene specific rev1 (5'-

TTAGGAACCGGTCTTGATTTTATAAGAC $-3^{`} \mathrm{~T}_{\mathrm{m}}=56^{\circ} \mathrm{C}$ ) and adaptor primers.

Gene specific primers (forv1, rev1) were designed to provide the overlapping of the obtained PCR products.

The PCR mixture contained $2 \mu \mathrm{l}$ of 1:50 cDNA dilution, PCR-buffer (Qiagen, Germany), 
GGCCAGGCGTCGACTAGTACTTTTTTTTTTTTTTTTT-3') according to manufacturer's

protocol. The cDNA was subjected to 2-round amplification with adapter and gene-specific

PCR mixture contained $1 \mu \mathrm{l}$ of cDNA, PCR Taq buffer (Invitrogen), $3 \mathrm{mM} \mathrm{MgCl} 2,100 \mu \mathrm{M}$

(each) dNTP, 5 pmol of each primer, and 1 unit of Platinum Taq DNA Polymerase (Invitrogen) in a total of $25-\mu 1$ reaction. Conditions of the reactions were as follows: 2 min of denaturation at $94{ }^{\circ} \mathrm{C} ; 5$ cycles of $15 \mathrm{~s}$ at $94^{\circ} \mathrm{C}, 15 \mathrm{~s}$ at $60^{\circ} \mathrm{C}, 5 \mathrm{~min}$ at $72^{\circ} \mathrm{C}, 35$ cycles of $15 \mathrm{~s}$ at $94^{\circ} \mathrm{C}, 15 \mathrm{~s}$ at $55^{\circ} \mathrm{C}, 5 \mathrm{~min}$ at $72^{\circ} \mathrm{C}$; and a final extension for $5 \mathrm{~min}$ at $72{ }^{\circ} \mathrm{C}$. stained with ethidium bromide.

A $2 \mu 1$ aliquot from the $1^{\text {st }}$ round was used for the $2^{\text {nd }}$ round of amplification with nested primers forv1N, forv2N (5'- GTTATTTTACTGATTTGGTTTTTATG -3' $\left.\mathrm{T}_{\mathrm{m}}=63^{\circ} \mathrm{C}\right)$ and adapter primer under the same conditions, but with $\mathrm{T}_{\mathrm{m}}$ increased by 2 degrees $\left(62^{\circ} \mathrm{C}\right.$ and $57^{\circ} \mathrm{C}$, respectively). The resulting amplificates were resolved by electrophoresis in $2 \%$ agarose gel and

\section{cDNA synthesis}

To obtain the full-length PCR-product of the studied gene we used cDNA prepared with SuperScript ${ }^{\mathrm{TM}}$ III Reverse Transcriptase (Invitrogen) with oligo(dT) primer on RNA from 293T cells and human tumors (patient codes 67, 82, 113, 156 and 246). cDNA was prepared as recommended by manufacturer.

To obtain the Biomedical Center human tumor cDNA panel we used Revert Aid ${ }^{\circledR}$ First Strand cDNA Synthesis Kit (Fermentas, Lithuania) with random hexamer primers on RNAs from different human tumors, following the manufacturer guidelines.

Obtained cDNA samples were stored at $-20^{\circ} \mathrm{C}$. The quality of the samples was assessed by PCR using primers for the housekeeping gene GAPDH (data not shown). 


\section{Two-round amplification of the full-length transcript}

Two-round PCR was performed with the primers for the obtained 5'end and 3'end: asforv $\quad\left(5^{\prime}-\quad\right.$ TGCACAGCATGCCCTAGAC-3' $\left.\quad \mathrm{T}_{\mathrm{m}}=60^{\circ} \mathrm{C}\right), \quad$ as-rev $\quad\left(5^{\prime}-\right.$ TTTTACTGATTTGGTCATTATG-3' $\left.3^{\prime} \quad \mathrm{T}_{\mathrm{m}}=61^{\circ} \mathrm{C}\right) \quad$ and full-forv $\quad$ (5'GTCTGAGCGTGAGCGAGAG-3' $\left.\quad \mathrm{T}_{\mathrm{m}}=62^{\circ} \mathrm{C}\right), \quad$ full-rev

ATGAAAAAAGAAAACGAGGTCTATT $\left.-3^{\prime} \mathrm{T}_{\mathrm{m}}=58^{\circ} \mathrm{C}\right)$.

The PCR mixture contained $1 \mu \mathrm{l}$ of cDNA, PCR-buffer High Fidelity (Invitrogen), $2 \mathrm{mM}$ $\mathrm{MgSO}_{4}, 100 \mu \mathrm{M}$ (each) dNTP, 5 pmol of each primer, and 1 unit of Platinum DNA Polymerase High Fidelity (Invitrogen) in a total of $25-\mu 1$ reaction. The first round of amplification was performed under the following conditions: 2 min of denaturation at $94{ }^{\circ} \mathrm{C} ; 40$ cycles of $15 \mathrm{~s}$ at $94^{\circ} \mathrm{C}, 20 \mathrm{~s}$ at $55^{\circ} \mathrm{C}, 3.5 \mathrm{~min}$ at $68^{\circ} \mathrm{C}$; and a final extension for $5 \mathrm{~min}$ at $68^{\circ} \mathrm{C}$. A $1 \mu 1$ aliquot from the $1^{\text {st }}$ round was used for the $2^{\text {nd }}$ round of amplification under the same conditions. The resulting amplificates were resolved by electrophoresis in $2 \%$ agarose gel and stained with ethidium bromide.

PCR

PCR primers targeting $O T P-A S 1$ conservation region were designed based on our sequence of OTP-AS1 from S1 Sequence. Forward primer 1012forv: 5'CACTTTCATGATATCTGCTGTTAC-3', reverse primer 1452rev: 5'ATAGTGTGCTGTAATTCCATTG-3'. The expected size of the amplicon was $440 \mathrm{bp}$ (from 1012 nucleotide to 1452 nucleotide of $O T P-A S 1$ sequence).

The PCR mixture contained $2.5 \mu 1$ of cDNA, PCR-buffer (67 mM Tris-HCl, $\mathrm{pH} 8.9,4$ $\mathrm{mM} \mathrm{MgCl} 2,16 \mathrm{mM}\left(\mathrm{NH}_{4}\right) \mathrm{SO}_{4}, 10 \mathrm{mM}$ 2-mercaptoetanol), $200 \mu \mathrm{M}$ (each) dNTP, 1 unit of Taq DNA polymerase (Fermentas, Lithuania), and $5 \mathrm{pmol}$ of each primer in a total of $25-\mu 1$ reaction 
volume. Amplification was performed with the following conditions: 1 min at $95^{\circ} \mathrm{C} ; 35$ cycles consisting of $30 \mathrm{~s}$ at $95^{\circ} \mathrm{C}, 30 \mathrm{~s}$ at $60^{\circ} \mathrm{C}$, and $60 \mathrm{~s}$ at $72^{\circ} \mathrm{C}$; and final elongation at $72^{\circ} \mathrm{C}$ for 5 min. All PCR products were analyzed by electrophoresis in $2 \%$ agarose gel and detected by staining with ethidium bromide.

\section{Sequencing}

PCR-products were extracted from the agarose gel, cloned into the pGEM-T Easy Vector (Promega) or TA cloning vector (Invitrogen), propagated in E.coli and sequenced using conventional techniques.

\section{Software and databases}

We used BioEditsoftware for basic manipulations with nucleic and amino acids sequences. Resources of the NCBI databases (http://www.ncbi.nlm.nih.gov/) and UCSC Genome Browser (GB) (http://genome.ucsc.edu/) were used extensively.

ORF search was performed with ORF Finder webtool (http://www.bioinformatics.org/sms2/orf_find.html). To analise the evolutionary age of the studied gene we used the bidirectional best hits $(\mathrm{BBH})$ method, which entails identifying the pairs of genes in two different genomes that are more similar (i.e., with highest alignment score) to each other than to any other gene. The orthologs were searched in 40 completely sequenced eukaryotic genomes which were retrieved from "Genome" resource (http://www.ncbi.nlm.nih.gov/genome/). The list of the used genomes is in S9 List. The nHMMER tool [22] and the original Shell script were used to perform homology search. For nHMMER an e-value threshold of $1 e^{-10}$ was specified. The first hit for query sequence within the program output was considered as the best hit. The very same procedure was performed for the results ran in the opposite direction, i.e. for the results where the subject genome was used as a query, and the query genome was used as a subject. 
Phylogram and cladogram of complete transcript and of its Eutheria-specific part were obtained

with MrBayes (v3.2.3) tool [23, 24]. More than 1000 iterations were implemented for bootstrap

procedure. Phylop tool integrated in USCS genome browser was used for conservation analysis.

The secondary structure of gene mRNA was modeled with RNAfold Web Server

(http://rna.tbi.univie.ac.at/cgi-bin/RNAWebSuite/RNAfold.cgi) [25, 26].

\section{References}

1. Baranova AV, Lobashev AV, Ivanov DV, Krukovskaya LL, Yankovsky NK, Kozlov AP. In

411 silico screening for tumour-specific expressed sequences in human genome. FEBS Lett. 2001; $412 \quad 508(1): 143-8$.

2. Krukovskaja LL, Baranova A, Tyezelova T, Polev D., Kozlov AP. Experimental study of 414 human expressed sequences newly identified in silico as tumor specific. Tumour Biol. 2005; $415 \quad 26(1): 17-24$.

3. Karnaukhova YK, Polev DE, Krukovskaya LL, Kozlov AP. The study of Orthopedia homeobox gene expression in different normal and tumor human tissues. Vopr Onkol. 2017; 63(1): 128-34. Russian.

4. Lin X, State MW, Vaccarino FM, Greally J, Hass M, Leckman JF. Identification, chromosomal assignment, and expression analysis of the human homeodomain-containing gene Orthopedia (OTP). Genomics. 1999; 60(1): 96-104. 
6. Nonaka D, Papaxoinis G, Mansoor W. Diagnostic Utility of Orthopedia Homeobox (OTP) in Pulmonary Carcinoid Tumors. Am J Surg Pathol. 2016; 40(6): 738-744.

7. The FANTOM Consortium and RIKEN Genome Exploration Research Group and Genome

Science Group. The Transcriptional Landscape of the Mammalian Genome. Science. 2005; 309: 1559-63.

8. Wright MW, Bruford EA. Naming 'junk': human non-protein coding RNA (ncRNA) gene nomenclature. Hum Genom. 2011; 5(2): 90-98.

9. Wright MW. A short guide to long non-coding RNA gene nomenclature. Hum Genomics. 2014; 8(1): 7 .

10. Nitsche A, Stadler PF. Evolutionary clues in lncRNAs. Wiley Interdiscip Rev RNA. 2017 Jan; 8(1).

11. Hutchinson JN, Ensminger AW, Clemson CM, Lynch CR, Lawrence JB, Chess A. A screen for nuclear transcripts identifies two linked noncoding RNAs associated with SC35 splicing domains. BMC Genomics. 2007; 8: 39.

12. Basu S, Müller F, Sanges R. Examples of sequence conservation analyses capture a subset of mouse long non-coding RNAs sharing homology with fish conserved genomic elements. BMC Bioinformatics. 2013; 14(Supp1 7): S14.

13. Johnsson P, Lipovich L, Grandér D, Morris KV. Evolutionary conservation of long noncoding RNAs; sequence,structure, function. Biochim Biophys Acta. 2014 Mar; 1840(3): 1063-71. with tumor-specific expression that is associated with a positive clinical outcome of cancer. 
15. Polev DE, Karnaukhova IK, Krukovskaya LL, Kozlov AP. ELFN1-AS1: A Novel Primate

449 Gene with Possible MicroRNA Function Expressed Predominantly in Human Tumors. Biomed $450 \quad$ Res Int. 2014; 2014: 398097.

16. Dobrynin P, Matyunina E, Malov SV, Kozlov AP. The Novelty of Human Cancer/Testis

Antigen Encoding Genes in Evolution. Int J Genomics. 2013; 2013: 105108.

17. Kozlov, A.P. Expression of evolutionarily novel genes in Tumors. Infect Agent 454 Cancer. 2016; 11:34.

18. Kornienko AE, Guenzl PM, Barlow DP, Pauler FM. Gene regulation by the act of long noncoding RNA transcription. BMC Biology. 2013; 11: 59.

19. Wang C, Gu Y, Zhang K, Xie K, Zhu M, Dai N, et al. Systematic identification of genes with a cancer-testis expression pattern in 19 cancer types. Nat Commun. 2016 Jan 27; 7: 10499.

20. Chirgwin JM, Przybyla AE, MacDonald RJ, Rutter WJ. Isolation of biologically active ribonucleic acid from sources enriched in ribonuclease. Biochemistry. 1979; 18(24): 5294-9. Spring Harbor Laboratory Press, Cold Spring Harbor, 2001.

22. Wheeler TJ, Eddy SR. nhmmer: DNA homology search with profile HMMs. Bioinformatics. 2013; 29(19): 2487-9.

23. Huelsenbeck JP, Ronquist F. MRBAYES: Bayesian inference of phylogenetic trees. Bioinformatics. 2001; 17: 754-5. models. Bioinformatics. 2003; 19: 1572-4. 
25. Gruber AR, Lorenz R, Bernhart SH, Neuböck R, Hofacker IL. The Vienna RNA Websuite.

470 Nucleic Acids Res. 2008 Jul 1; 36(Web Server issue): 70-74.

26. Lorenz R, Bernhart SH, Höner Zu Siederdissen C, Tafer H, Flamm C, Stadler PF, et al.

ViennaRNA Package 2.0. Algorithms Mol Biol. 2011; 6: 26.

Fig 1. Two-round amplification of the studied gene 5 ' end using gene specific and adaptor primers.

4761 - adaptor primer and $\operatorname{rev}(\mathrm{N})$

2 - negative control, first round of PCR, no template added

3 - negative control, second round of PCR, no template added

M1 - GeneRuler ${ }^{\mathrm{TM}} 100$ bp DNA ladder (Fermentas)

M2 - GeneRuler ${ }^{\mathrm{TM}} 1 \mathrm{~kb}$ DNA ladder (Fermentas)

Fig 2. Exon/intron borders of the studied gene.

* gt - donor splicing site

**ag - acceptor splicing site

Fig 3. Two-round amplification of the studied gene 3' end using gene specific and adaptor primers.

1 - adaptor primer and forv $1(\mathrm{~N})$

489

2 - negative control, first round of PCR, no template added 
3 - adaptor primer and forv2(N)

4 - negative control, second round of PCR, no template added

$\mathrm{M}$ - GeneRuler ${ }^{\mathrm{TM}} 1 \mathrm{~kb}$ DNA ladder (Fermentas)

Fig 4. Genome localization of $O T P$ gene and its sequenced fragments

Schematic alignment of the sequenced fragments ( 5 ' end fragment - yellow, 3' end fragment №1 - green, 3'end fragment №3 - cyan, assembled full-length sequence - red) with the 5th chromosome (black) and the OTP gene (blue).

\section{Fig 5. Two-round amplification of the full transcript on the cDNA from:}

$1-293$ T cells

2 - uterus endothelium adenocarcinoma

3 - negative control, first round of PCR, no template added

4 - negative control, second round of PCR, no template added

M1 - GeneRuler ${ }^{\mathrm{TM}} 100$ bp DNA ladder (Fermentas)

M2 - GeneRuler ${ }^{\mathrm{TM}} 1 \mathrm{~kb}$ DNA ladder (Fermentas)

\section{known ESTs.}

The least conserved genomic DNA sequence is highlighted with blue. The most conserved genomic DNA sequence is highlighted with yellow. (This scheme was obtained with UCSC Genome Browser tool). 
Fig 7. The lack of expression of the newly discovered gene conservative region in normal human tissues.

a) 1 - normal brain, 2 - normal heart, 3 - normal kidney, 4 - normal liver, 5 - normal lung, 6 normal pancreas, 7 - normal placenta, 8 - normal skeletal muscle, K- - PCR with no template, $\mathrm{K}+-\mathrm{PCR}$ with human DNA.

b) 1 - normal colon, 2 - normal ovary, 3 - normal peripheral blood leukocytes, 4 - normal prostate, 5 - normal small intestine, 6 - normal spleen, 7 - normal testis, 8 - normal thymus, K- PCR with no template, $\mathrm{K}+-\mathrm{PCR}$ with human DNA.

c) 1 - normal bone marrow, 2 - fetal liver, 3 - normal lymph node, 4 - normal peripheral blood leukocyte, 5 - normal spleen, 6 - normal thymus, 7 - normal tonsil, K- - PCR with no template, $\mathrm{K}+-\mathrm{PCR}$ with human DNA.

d) 1 - fetal brain, 2 - fetal heart, 3 - fetal kidney, 4 - fetal liver, 5 - fetal lung, 6 - fetal skeletal muscle, 7 - fetal spleen, 8 - fetal thymus, K- - PCR with no template, K+ - PCR with human DNA.

\section{Fig 8. Expression of the newly discovered gene conservative region in human tumors.}

a) 1 - brain astrocytoma, 2 - breast invasive ductal carcinoma, 3 - lung squamous cell carcinoma,

4 - esophagus adenocarcinoma, 5 - stomach adenocarcinoma, 6 - small intestine adenocarcinoma, 7 - colon adenocarcinoma, 8- hepatocellular carcinoma, 9- kidney clear cell carcinoma, 10 - bladder transitional cell carcinoma, 11- uterus adenocarcinoma, 12 - fallopian tube medullary carcinoma, 13 - ovary mucinous adenocarcinoma, 14 - testis seminoma, 15ureter papillary transitional cell carcinoma, K- - PCR with no template, K+ - PCR with human DNA.

b) 19 - stage III mammary gland adenocarcinoma, 246, 250, 251, 252 - stage II-III invasive duct mammary gland cancer; 2 - squamous cell cervical carcinoma IV stage and its metastases into uterus (2a-1), left (2a-3) and right ovary (2a-4), 13- cervical myosarcoma, stage II-III, 6 - ovary 
cancer, 156 - stage II moderately differentiated endometrial adenocarcinoma, 270 - stage III moderately differentiated endometrial adenocarcinoma with metastases, 7 - seminoma, 45, 63 -

540 meningiomas, 140 -hypophyseal adenoma, 12,14 - squamous cell lung cancer, 17 - bronchus

541 cancer III stage, 108 -stomach cancer, 30 - stage IV chronic lymphacytic leukemia, 31 - stage IV non-Hodgkin T-cell lymphoma, 67 - lymphoadenpathy of unclear pathogenesis, 82 - stage II non-Hodgkin lymphoma, stage II, 92 - stage IV Hodgkin's lymphoma, 94 - hemolythic anaemia of unclear pathogenesis, 102 - stage II non-Hodgkin lymphoma, 113T - stage IV non-Hodgkin lymphoma, K- - PCR with no template, $\mathrm{K}+-$ PCR with human DNA.

Fig 9. Two-round amplification of the studied transcript on the cDNA from differend clinical tumor subjects.

1- lymphadenopathy of unknown origine (67)

2- non-Hodgkin's lymphoma at stage II (82)

3 non-Hodgkin's lymphoma at stage IV (113)

4 - invasive ductal breast cancer at stage II (246)

6 - negative control, first round of PCR, no template added

7 - negative control, second round of PCR, no template added

8 - positive control, first round of PCR with plasmid containing full transcript of newly identified gene

9 - positive control, second round of PCR with plasmid containing full transcript of newly 


\section{Supporting Information}

564 S1 Sequence. Sequence of the 5' end of the transcript.

565 S2 Sequence. Sequence of the fragment №1 of the 3' end of the transcript.

566 S3 Sequence. Sequence of the fragment №3 of the 3' end of the transcript.

567 S4 Sequence. Sequence of the the full lenght transcript of the study gene (OTP-AS1).

568 S5 List. Amino acid sequences of ORFs.

569 S6 Figure. Secondary structure of OTP-AS1 mRNA.

570 S7 Figure. Phylogram of complete sequence of $O T P$ - $A S 1$ gene orthologs based on average

571 branch lengths.

572 S8 Figure. Phylogram of the evolutionary novel part of OTP-AS1 gene orthologs based on 573 average branch lengths. 
bioRxiv preprint doi: https://doi.org/10.1101/350793; this version posted June 19, 2018. The copyright holder for this preprint (which was not certified by peer review) is the author/funder, who has granted bioRxiv a license to display the preprint in perpetuity. It is made available under aCC-BY 4.0 International license. 
bioRxiv preprint doi: https://doi.org/10.1101/350793; this version posted June 19, 2018. The copyright holder for this preprint (which was not certified by peer review) is the author/funder, who has granted bioRxiv a license to display the preprint in perpetuity. It is made available under aCC-BY 4.0 International license. 
DNA agatcotgag togactccet ogtpogtaa atggcgggaa 
Fragment №1 2311 bp

Fragment №2 $\sim 1100$ bp

Fragment №3 940 bp 
$\begin{array}{lllllll}\text { M1 } & \text { M2 } & 1 & 2 & 3 & 4 & \text { M1 }\end{array}$ 


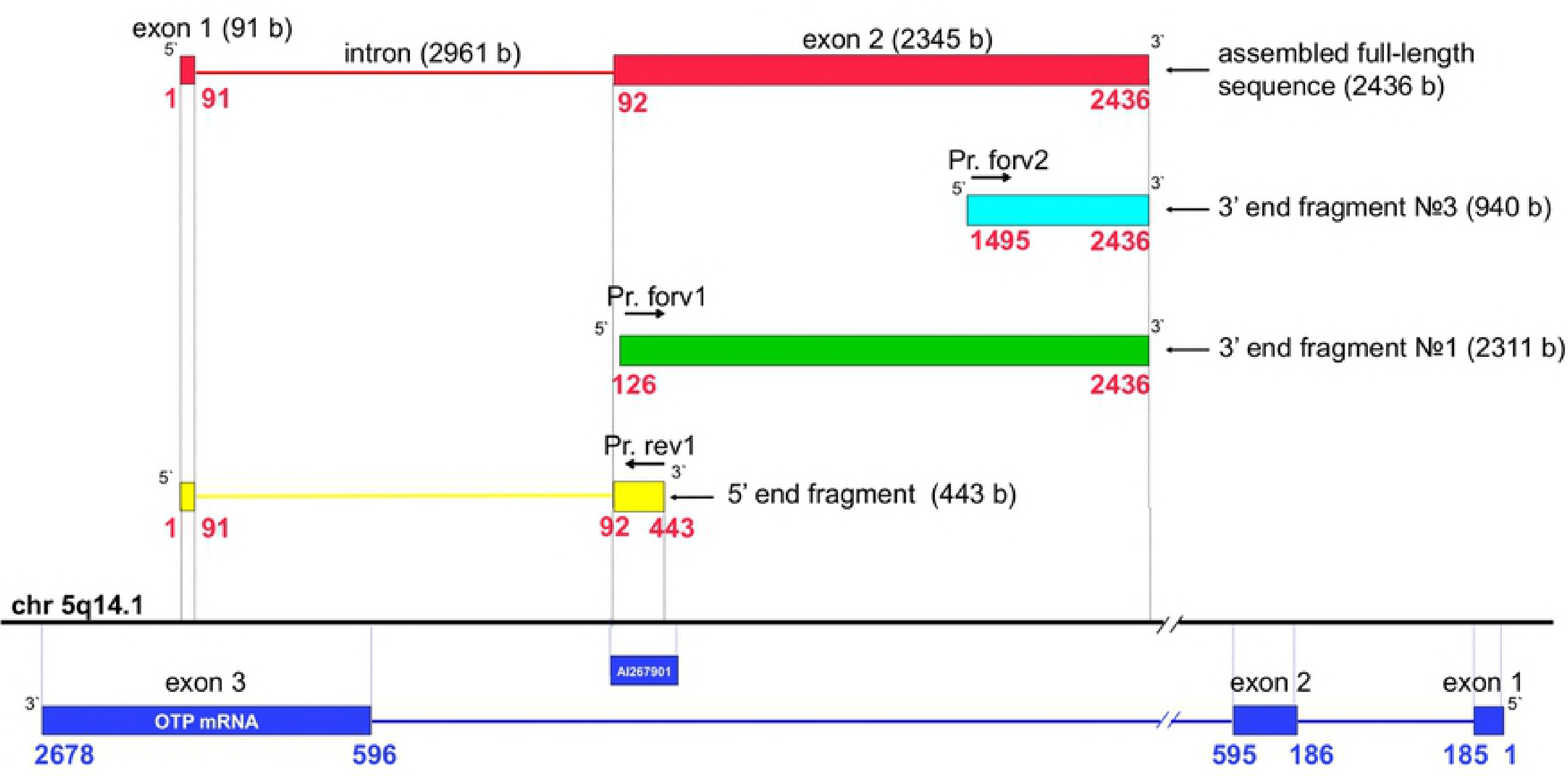


chrs (q14.1)

$76,930,0001$
Your sequence from Blat search

Newly discovered gene OTP

คคะ856 74

AI 733048

คคB

A1732914

BE618117

BE6 18703

AI 6933 es

คA973827

คค 41578

AA 416782

AW134781

A1791530

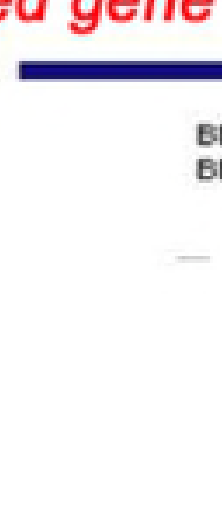

UCSC Genes (Rerseq, GenBank, CCDS, Rfam, tRNAs \& Comparat ive Genomics)

EESS9799 Human ESTs Including Unsp 1 iced

BE327227 BG149719 BE671464

BF512795H BE218748

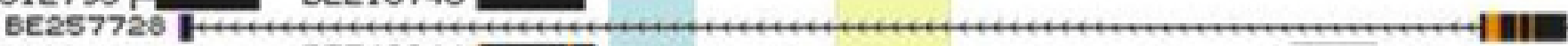

BE5 49644

AI 694135

BX111163

BES 93736

AI 697819

A1697819

EE 0.45373

BFo23543

AW444662

BEF 671531

A1267991

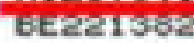

BE221374

$4.88-$

1 e日 vert. Cons

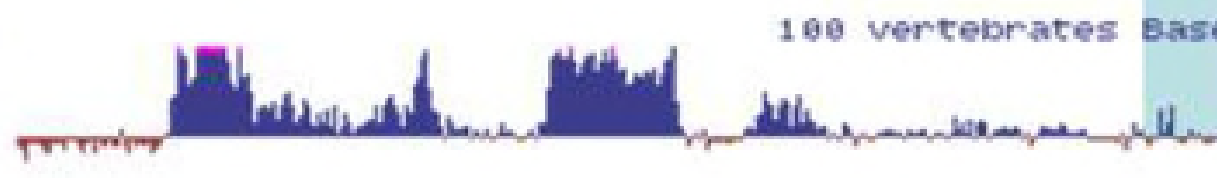

ise conservat ion by phy lop

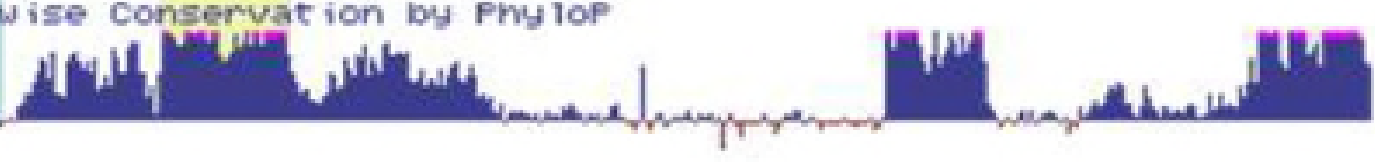


a) \begin{tabular}{lllllllll}
1 & 2 & 3 & 4 & 5 & 6 & 7 & 8 & $\mathrm{~K}-\mathrm{K}+$ \\
& & & & & & & & \\
\hline
\end{tabular}

Human MTC Panel I (Clontech, USA) b)

Human MTC Panel II (Clontech, USA)

d) $\begin{array}{lllllllll}1 & 2 & 3 & 4 & 5 & 6 & 7 & 8 & \mathrm{~K}-\mathrm{K}+ \\ & & & & & & & & \end{array}$

Human Fetal MTC Panel (Clontech, USA) 

$\begin{array}{llllll}M 1 & 1 & 2 & 3 & 4 & 5\end{array}$

6

2378 bp

$8 \mathrm{M} 1$ 